\title{
Inferindo sobre aprendizagem via experimentos de física elaborados com material de baixo custo
}

\author{
Inferring on learning by physical experiments mounted with low cost materials \\ I. L. Furtado*; F. C. L. Ferreira; J. E. Oliveira; F. F. de Sousa \\ Instituto de Ciências Exatas, Universidade Federal do Sul e Sudeste do Pará, CEP: 68505-080, Marabá-PA, Brasil \\ *m1nnylemos@gmail.com
}

(Recebido em 28 de novembro de 2016; aceito em 28 de dezembro de 2016)

\begin{abstract}
O resumo deve ser inserido aqui e não pode ultrapassar Este trabalho foi desenvolvido com objetivo de inferir sobre a aprendizagem de conceitos de Física usando como metodologia experimentos de física elaborados a partir de materiais de baixo custo. Para isso, foram desenvolvidas atividades experimentais na sala de aula de uma escola municipal da cidade de Marabá (Pará). Os estudantes escolhidos para o desenvolvido das atividades propostas neste trabalho foram os do $9^{\mathrm{a}}$ ano. Como referencial teórico utilizouse da aprendizagem significativa de David Ausubel. A pesquisa mostra que é possível estabelecer ótima relação entre o aprendizado dos conceitos de Física e a disposição dos discentes em aprender, o que foi constatado por meio do entusiasmo, motivação, interesse em descobrir além dos conceitos apresentados em sala de aula e do nível de compreensão manifestada por eles. Neste processo, o papel do docente é importante ao conduzir esse tipo de atividade para alcançar bons resultados no ensino e aprendizagem, mas é imprescindível que os discentes sintam-se instigados e motivados à aprender algo proposto. Tal resultado está relacionado às respostas dos discentes referentes aos questionários aplicados, os quais promoveram momentos para analisar e avaliar os seus próprios conhecimentos. Desse modo, este trabalho permitiu aos discentes a pensar de forma diferente, bem como promovendo uma visão diferenciada sobre os conceitos de Física. Talvez isto possa ser considerado como um grande desafio, mas podendo ser superado com a utilização de modelos práticos, situações cotidianas e vivenciadas pelo discente, mostrando uma Física não dogmática, mais crítica e palpável.

Palavras-chave: Experimentação no ensino de Física, Aprendizagem significativa, Ensino fundamental.
\end{abstract}

The work was performed with the goal of inferring about learning of physics concepts using as a methodology physics experiments, which were mounted with low cost materials. Thus, experimental activities were in classroom from a public school of Maraba city (Pará). The students selected to participate of the proposal activities in this work were of the $9^{\text {th }}$ year. The referential utilized was based about David Ausubel's theory. This research shows that is possible to establish a relationship between the learning on concepts of Physics and the disposition of the students at to learn, as was verified through the enthusiasm, motivation at discover beyond of the concepts presented at classroom, and the level from comprehension manifested by them. In this process, the role of the teacher is important for to conduct these type activity for to achieve good results in the teaching and in the learning, however is indispensable that the students feel encouraged and motivated to learn something proposed. Such resulted is related to the students' answers regarding the applied questionnaires, which promoted moments to analyze learning and evaluate their own knowledge. Thus, this work allowed to the students to differentiated thinking, as well as promoting a critical view on the concepts of Physics. Perhaps this can be considered a great challenge, but it can be overcome with the use of practical models, day-to-day situations and experienced by the student, showing non-dogmatic, more critical and realistic physics.

Keywords: Experiments in the physics teaching, Meaningful learning, Elementary school

\section{INTRODUÇÃO}

Um dos maiores desafios diante do ensino de ciências, em particular no ensino de Física, é construir a ligação entre o conhecimento escolar e o mundo vivenciado pelos alunos no seu cotidiano. A ausência deste vínculo pode proporcionar o desânimo e o distanciamento entre os alunos e a motivação em aprender. Por outro lado, ao restringir o ensino a uma abordagem tradicional e formal, o professor acaba não utilizando os mecanismos necessários para tornar a 
Física mais "atraente", com isso perde-se a oportunidade de associá-la com cotidiano dos alunos [1]. Uma forma de transformar a Física em uma ciência mais atraente é utilizando experimentos no ambiente escolar, transformando a sala de aula em um ambiente de confirmação de teorias, de investigações e principalmente em um local de aprendizagem, desenvolvendo consequentemente o senso crítico do aluno [2]. Neste trabalho, foram elaborados vários experimentos de Física com material de baixo custo e, em seguida, apresentados aos alunos (3 turmas) do $9^{\circ}$ ano da Escola Martinho Motta do Município de Marabá na forma de aula prática para inferir sobre a aprendizagem de alguns conceitos de Física, envolvendo pressão, calor, espelhos planos e propagação do som. As práticas foram apresentadas aos alunos baseando-se na teoria da aprendizagem significativa de Ausubel [3], a qual afirma que a aprendizagem será significativa mediante predisposição do aluno em estar motivado para aprender determinado tema ou conceito. Dessa forma, o intuito é fazer com que os alunos aprendam conceitos de Física de modo efetivo e prazeroso através de aulas praticas, usando principalmente aqueles conceitos circundantes ao seu cotidiano e, já preexistentes em sua estrutura cognitiva.

\section{FUNDAMENTAÇÃO TEÓRICA}

Apesar dos problemas encontrados no ensino de Física atualmente, podemos proporcionar aos alunos atividades contendo conceitos que façam parte de seu cotidiano, e que estas tenham significados, sejam motivadoras e despertem o espírito da curiosidade. Além disso, elas devem permitir a observação crítica e, mostrem o extraordinário no ordinário, por exemplo, que os alunos possam enxergar a Física num jogo de basquete, no cozimento do alimento, na formação do arco-íris, ou simplesmente no fato de estarem sempre presos ao chão sem conseguirem levitar [4].

Os alunos têm o papel de ouvintes e, na maioria das vezes, os conhecimentos transmitidos pelos professor não são realmente absorvidos por eles, são apenas memorizados por um curto período de tempo e, em geral, esquecidos posteriormente, comprovando a não ocorrência de um aprendizado significativo. Segundo Ausubel [3], para a aprendizagem ser significativa no processo de ensino necessita fazer algum sentido para o aluno e, desse modo, a informação deverá interagir e ancorar-se nos conceitos relevantes já existentes na estrutura cognitiva do aluno. $\mathrm{O}$ autor entende que a aprendizagem significativa se verifica quando o banco de informações no plano mental do aluno se revela, através da aprendizagem por descoberta e por recepção. O processo utilizado para as crianças menores é o de formação de conceito, envolvendo generalizações de interesses específicos para na idade escolar e que já tenham desenvolvido um conjunto de conceitos, de modo a favorecer o desenvolvimento da aprendizagem significativa [5].

\section{METODOLOGIA}

A metodologia experimental usada na sala de aula é uma alternativa que pode auxiliar os professores no processo de ensino-aprendizagem [6]. Em nosso trabalho, os conceitos de Física foram escolhidos de modo que os discentes percebessem que tais conceitos estão presentes no seu dia-a-dia e que os fenômenos observados, por meio dos experimentos propostos, atraíssem a atenção.

Os experimentos foram confeccionados com materiais de baixo custo e bem simples, em seguida, levados à sala de aula. No momento de realização dos experimentos, os discentes foram convidados a participarem, com objetivo de que eles pudessem interagir de maneira efetiva com o desenvolvimento da aula experimental. O professor da disciplina de ciências também participou para que o mesmo pudesse perceber a diferença que uma aula prática faz. 
Após a realização dos experimentos, foram introduzidas perguntas na forma de questionário, para investigar e verificar se realmente os discentes conseguiram absorver tais conceitos e saber se eles aprenderam de forma prazerosa. O trabalho foi aplicado em uma turma do $9^{\mathrm{a}}$ ano da Escola Municipal de Ensino Fundamental Martinho Motta da Silveira. Notou-se que a turma que fez parte do trabalho nunca teve contato com experimentos de física em sala de aula. A turma teve aula teórica, mas sem o uso de experimentos sobre os assuntos propostos (mecânica, óptica, calor e acústica) neste trabalho.

Os experimentos apresentados aos alunos abordaram os seguintes conceitos: pressão, calor, espelhos planos e propagação do som. Logo abaixo, são mostrados na Figura 1 alguns dos experimentos utilizados em sala de aula, nos quais foram usados materiais simples e de fácil acesso, como placa de isopor, pregos, balões, vela, fio de barbante e espelhos. Materiais que os próprios discentes não acreditavam que seria possível vê Física com esses experimentos simples e, não imaginavam, que todos os conceitos estão presentes no seu cotidiano.
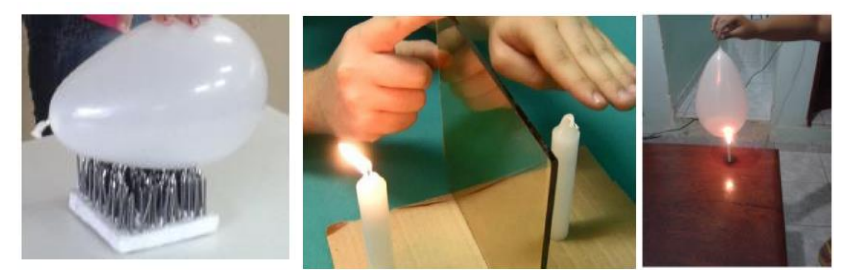

Figura 1: Ilustração de alguns experimentos de física utilizados na sala de aula.

\section{RESULTADOS E DISCUSSÃO}

Após a aplicação do questionário, o que chamou mais atenção foi o fato de que os depoimentos, de modo geral, tiveram para cada aluno um significado muito especial; além de simplesmente reproduzir experimentos, mostrou o despertar para o estudo da Física. Com a aula prática, notamos que o aluno começa a buscar na Física explicações para suas curiosidades pessoais, o que é de suma importância, pois esta matéria de colégio começa a fazer sentido para sua vida, para seu crescimento intelectual. É importante destacar nesse contexto que se esse momento não tiver qualidade, interatividade e significância, ou seja, se o que tiver sendo apresentado para o aluno não for significativo, os resultados poderão ser catastróficos.

"[...] me mostrou outro lado da física. Porque até então eu via a Física como uma matéria chata, sem dinâmica, só com conta, em fim, não tinha nenhum interesse pela Física. Depois da experiência eu vi que a Física é bem maior e bem mais interessante do que eu pensava."

“[...] Os discentes se sentiram mais motivados a aprender, a estudar, a fazer, e a interagir mais com a matéria."

Nas falas desses alunos, percebemos que experimentação, para eles, é um fator motivante no estudo dos conceitos de Física, pois neste momento seu papel foi muito além de um simples aprendiz: eles participaram ativamente nas reflexões e, principalmente, na execução do trabalho. Neste momento vale ressaltar, que o sujeito de sua aprendizagem é quem realiza a ação, e não alguém que sofre ou recebe uma ação.

Vejamos logo a seguir os relatos de mais dois alunos retratando a eficiência, os benefícios e até comparação da metodologia experimental com outros métodos em que se utiliza a internet como ferramenta para alcançar a aprendizagem. 
“[...] eu prefiro muito mais um trabalho prático (experimento) do que um trabalho que você só precisa ir na internet e pronto." "[...] achei legal esta atividade, bastante interessante, eu aprendi mais claramente. E vi que a Física tem tudo haver com as coisas do nosso mundo."

$\mathrm{Na}$ análise foi observado que os alunos entrevistados conseguiram fazer algum tipo de associação entre o experimento produzido com seu cotidiano. Tal constatação nos leva a crer que esses alunos assimilaram o conteúdo físico envolvido no trabalho, logo, a aprendizagem efetiva aconteceu para eles. Isto mostra que não se pode descartar a utilização desta atividade no ensino de Física.

Mais adiante dispomos de mais cinco relatos de outros alunos, os quais demonstram sobre a facilidade, a descontração e o prazer em aprender Física mediante o uso de aulas práticas confeccionadas com materiais de baixo custo; e do modo como foi proposto neste trabalho.

\section{“[...] com muito prazer e muita vontade faria tudo de novo." \\ "[...] foi algo que me interessou, que eu fiz com prazer." \\ "[...] é mais fácil aprender a matéria com esse tipo de atividade." \\ "[...] a aula se torna muito interessante, ou seja, possibilita uma maneira mais dinâmica de ensino-aprendizado." \\ "[...] Foi muito interessante, por que nós gostamos de aprender de uma forma descontraída, e porquê além de ser uma coisa nova é diferente para nós, nós aprendemos."}

É notadamente observado, ao analisar as respostas desses alunos, que eles se empolgam ao falar da maneira como vê a experimentação no ensino de Física. Sabe-se que, para ocorrer a aprendizagem significativa é necessário que o aluno tenha disposição pra aprender, e esses alunos após a aula prática, se doaram para aprender. Eles classificaram a produção de experimentos como uma atividade divertida e prazerosa, pois, pelo fato de terem muita liberdade para escolher o material e produzir a atividade. Após ministrar a aula com o uso da experimentação, notamos que o aluno começa a buscar na Física explicações para suas curiosidades pessoais, o que é de suma importância, pois esta matéria começa a fazer sentido para sua vida, para seu crescimento intelectual.

Foi observado em vários relatos que o termo motivação é explícito por parte do aluno. Em todas as falas observadas até então, o aluno tem-se apresentado mais disposto e motivado a aprender Física. A aprendizagem é resultado de ações de um sujeito, não é resultado de qualquer ação: ela se constrói em uma interação entre esse sujeito e o meio circundante, natural e social. Segue abaixo os relatos de dois dos alunos, os quais permitiram verificar que a aula significou muito para eles, bem como para os demais. Depois dos experimentos observamos um interesse maior dos alunos pela Física.

Pode-se afirmar, que a experimentação pode não garantir o aprendizado definitivo do aluno, mas é um fator de extrema importância para que ele se envolva mais no processo de ensino-aprendizagem; em outras palavras, é o que estimula o aluno a estudar, fator determinante para o processo.

Sabe-se, com base na vivência cotidiana, que as pessoas aprendem o tempo todo. Instigadas pelas relações sociais ou por fatores naturais, aprendem por necessidades, interesses, vontade, enfrentamento.

Nesses relatos mostrados e discutidos acima, fica claro a expressão de motivação que é um fator inovador para os alunos, bem como o entusiasmo e a curiosidade de cada um. Ficou claro que conseguimos mais atenção deles mesmo desenvolvendo práticas simples e com materiais de fácil acesso. Eles ficaram mais dispostos a se aprofundar nos conceitos, além de se 
dedicarem mais após a aprendizagem. Por fim, não há como ensinar alguém que não quer aprender, uma vez que a aprendizagem é um processo interno que ocorre como resultado da ação de um jeito, na vivência cotidiana, que as pessoas aprendem o tempo todo.

\section{CONCLUSÃO}

Neste trabalho, experimentos envolvendo conceitos de Física elaborados com materiais de baixo custo e simples, foram usados como práticas em sala de aula, neste caso com alunos do nono ano de uma escola pública do município de Marabá. Percebeu-se, que o professor ainda encontra-se ligado aos paradigmas estabelecidos durante décadas pelo ensino tradicional, pois os mesmos não se preocupam em buscar novas metodologias ou ferramentas para obtenção de melhores resultados em sala de aula. A realização das aulas práticas usando os experimentos de Física permitiu maior envolvimento dos alunos com o professor e entre seus colegas, trocando ideias sobre os experimentos, de maneira que a aula tornou-se, além de mais dinâmica, mais interativa. Além disso, verificou-se a importante de que os profissionais da educação tenham uma visão cada de vez mais aberta sobre os recursos e metodologias que auxiliem no ensino, por exemplo, desenvolvendo projetos que venham contribuir de forma positiva para o enriquecimento do processo de ensino aprendizagem, pois o ensino não pode continuar de forma tradicional e, sim, buscar metodologias inovadoras de ensino para contribuir para uma boa aprendizagem. Portanto, o desenvolvimento deste trabalho mostrou que os experimentos em sala de aula proporciona ao aluno uma visão diferenciada da Física, que ainda é um grande desafio, o qual pode ser vencido com a utilização metodologias simples e práticas a partir de situações reais e vivenciais pelo aluno.

\section{REFERÊNCIAS BIBLIOGRÁFICAS}

[1] Brasil. Secretaria da Educação Média e Tecnologia - Ministério da Educação e Cultura. Parâmetros Curriculares Nacionais - Ensino Médio; Ciências da Natureza, Matemática e suas tecnologias. Brasília: MEC/SEMTEC; 2006.

[2] Bondia, JL Notas sobre a experiência e o saber de experiência. Revista Brasileira de Educação 2002 ; v. 19: 20-28, doi:10.1590/S1413-24782002000100003

[3] Ausubel, D.P.A aprendizagem significativa: a teoria de David Ausubel. São Paulo: Moraes; 1982.

[4] S.-Neves M, Caballero C, Moreira MA. Repensando o papel do trabalho experimental, na aprendizagem da física, em sala de aula - um estudo exploratório 2006; 11(3): 383-401.

[5] Corci MB, Fusinato AP, Blini RB. Reflexões sobre a importância da experimentação no ensino de física 2009; 31(1): 43-49, doi:10.4025/actascihumansoc.v31i1.380

[6] Matos MG, Valadares J, O efeito da actividade experimental na aprendizagem da ciência pelas crianças do primeiro ciclo do ensino básico 2001; 6(2): 227-239 